\title{
Researches on the Enhancement of Plasticity of Bulk Metallic Glass Alloys
}

\author{
Byoung Jin Kim, Won Tae Kim ${ }^{1, *}$ \\ Center for Non-crystalline Materials, Yonsei University, Seoul 120-749, Korea \\ ${ }^{1}$ Department of Laser \& Optical Information Engineering, Cheongju University, Cheongju 363-764, Korea
}

*Correspondence to: Kim WT,

Tel: +82-43-229-8551

Fax: +82-43-229-8498

E-mail: wontae@cju.ac.kr

Received June 17, 2015

Revised June 24, 2015

Accepted June 24, 2015
Bulk metallic glass (BMG) shows higth strength, high elastic limit, corrosion resistance and good wear resistance and soft magnetic properties and has been considering as a candidate for new structural materials. But they show limited macroscopic plasticity and lack of tensile ductility due to highly localized shear deformation, which should be solved for real structural application. In this paper researches on the enhancement of plasticity of BMG were reviewed briefly. Introducing heterogeneous structure in glass is effective to induce more shear transformation zones (STZs) active for multiple shear band initiation and also to block the propagating shear band. Several methods such as BMG alloy design for high Poisson's ratio, addition of alloying element having positive heat of mixing, pre-straining BMG and variety of BMG composites have been developed for homogenous distribution of locally weak region, where local strain can be initiated. Therefore enhancement of plasticity of BMG is normally accompanied with some penalty of strength loss.

Key Words: Bulk metallic glass, Bulk metallic glass composite, Plasticity

\section{INTRODUCTION}

Metallic glass exhibits exotic properties such as high strength, high elastic limit, corrosion resistance, good wear resistance and soft magnetic properties, which are originated from dense random packing of consisting elements (Ashby \& Greer, 2006). Since the report of bulk metallic glass (BMG) formation in a Zr-based system (Zhang et al., 1991), there has been a great effort to find the alloy systems with a high glass forming ability. BMGs are developed in many alloy systems and critical size of BMG can be reached about a few centimeters (Nishiyama et al., 2013). BMGs have been considered to have potential application as a new type of structural materials due to the excellent mechanical properties. However, BMGs are usually macroscopically brittle especially at room temperature, preventing their structural application.

Due to the absence of dislocation in metallic glass, plastic flow in metallic glasses is produced by local shear deformation and their coalescence and propagation (Falk \& Langer, 1998; Lund \& Schuh, 2003). BMG shows strain softening which is contrary to strain hardening in crystalline materials. Local deformation in shear band occurs by cooperative rearrangement of local clusters. Due to the strain softening in shear band, once it forms then it travels across the entire specimen, resulting in catastrophic failure especially in tensile mode. Even though some metallic glasses have found successful applications in functional areas such as soft magnetic materials and filler metals in brazing, the structural application was hindered by the limited plasticity. Many works have been performed to tackle this problem by tuning alloy chemistry to develop tough BMG and provide plasticity (Hofmann et al., 2008).

The enhancement of plasticity in metallic glass can be realized through the relaxation of localized deformation. The relaxation can be achieved by distributing induced strain

This work was supported by the research grant of Cheongju University in 2014.

@ This is an open-access article distributed under the terms of the Creative Commons Attribution Non-Commercial License (http://creativecommons.org/licenses/by-nc/4.0) which permits unrestricted noncommercial use, distribution, and reproduction in any medium, provided the original work is properly cited.

Copyrights (c) 2015 by Korean Society of Microscopy 
more uniformly through a specimen. These can be provided by introducing a microstructural heterogeneity, ranging from atomic scale to $\mu \mathrm{m}$ scale in length. Several methods have been used to improve plasticity of BMG such as alloy design for high Poisson's ratio (Schroers \& Johnson, 2004; Liu et al., 2007; Yokoyama et al., 2009; Greaves et al., 2011), addition of element having positive heat of mixing (Park et al., 2005a; Liu et al., 2013), pre-straining BMG (Park et al., 2005b; Wang et al., 2014) and various BMG composites. The purpose of all of the methods is to increase the density of shear bands in order to dissipate the deformation energy into much larger volume by distributing regions of weak resistance to shear or second particles of different elastic modulus and strength from those of matrix. In this paper, the progress in research on the enhancement of plasticity of BMG alloys will be reviewed briefly.

\section{DEFORMATION IN METALLIC GLASS}

Before describing the deformation mode in metallic glass, it may be worth of mentioning the main features of deformation in crystalline materials, which is characterized by strain hardening behavior. The dominant deformation mechanism in crystalline alloys is dislocation processes especially at normal temperature. Under an applied stress, dislocations on a slip plane start to move through the lattice without any change in volume when the resolved shear stress on that plane reaches a critical value. As they move, they encounter obstacles hindering the dislocation movement. For further movement of dislocation, the resolved shear stress should be increased further to overcome the obstacles such as solute atoms, particles and grain boundaries. The dislocation density increases with increasing strain. With this increasing dislocation density it becomes increasingly difficult to deform the material. This process is called strain hardening. This strain hardening allows the crystalline materials to experience uniform deformation before geometrical instability takes place. In reality necking takes place in tensile deformation when the strain hardening rate becomes equal to the thinning rate of specimen. Therefore strain hardening behavior plays an important role in stabilizing mechanical instability and promoting uniform deformation. Strain hardening index can be considered as a measure of the resistance to the onset of instability.

Metallic glasses are featured with random packing of constituting elements without any long range order. Due to the absence of dislocation, the deformation mode in metallic glass is different from the dislocation process in crystalline materials and strain hardening behavior is rarely expected in BMG. Free volume theory (Spaepen, 1976) and shear transformation zone (STZ) models (Falk et al., 1998) are commonly referred as models for deformation in metallic glass. In free volume model, atom can move into a free volume when the local free volume is larger than a critical value. Therefore shear deformation requires free volume. Local regions having more free volume can be deformed more easily at lower applied stress. The free volume theory can describe macroscopic deformation behavior in metallic glasses, in which the dilatational deformation is localized and this localization will give rise to the change of viscosity and finally results in the inhomogeneous plastic flow. Once a shear band is initiated, it could traverse the entire cross section of the specimen in unconfined tensile mode. In STZ model, STZ corresponding to a region of low shear modulus or of weak resistance to shear was introduced and deformation in metallic glass proceeds by collective rearrangement of STZ, and the coalescence of STZs forms shear band (Lund \& Schuh, 2003). Following the deformation models in BMG, enhancement of plasticity of BMG can be realized by introducing various types of structural heterogeneity, acting as potential sites to initiate shear band and block the propagation of shear band for relaxation of localized shear deformation.

\section{BMG WITH HIGH POISSON'S RATIO}

Most BMGs show a limited plasticity even in a compression mode and no ductility in unconfined tensile mode. Even the glass showing fracture toughness comparable to the toughest materials showed very limited tensile elongation (Demetriou et al., 2011). Currently, it is not clear about the intrinsic factors that affect the macro-plasticity of monolithic BMG. Some researches indicate that there is a certain correlation between the Poisson ratio and plasticity of BMG (Lewandowki et al., 2005). BMGs having a higher Poisson ratio often showed a better plasticity.

For isotropic solid like BMG, Poisson's ratio $v$ is related to the ratio of shear modulus $G$ and bulk modulus $B$ as follows.

$$
v=(3-2 G / B) /(6+2 G / B)
$$

In a meaning full range of $\mathrm{G} / \mathrm{B}, v$ increases with decreasing $\mathrm{G} / \mathrm{B}$. Therefore $v$ can be considered as a relative easiness of shear deformation with respect to the resistance of volume change. A higher $v$ decreases the potential energy of the STZ, thereby increasing the tendency of plastic deformation in mitigating fracture stress concentration (Poon et al., 2008). Lewandowki et al. (2005) proposed a critical value of $v$ (0.31 0.32) at which brittle to tough transition occurs in BMG. Liu et al. (2007) studied the correlation between the ductility and composition in $\mathrm{Zr}$-Ti-Ni-Al system and showed BMG having higher $v$ showed larger plastic strain before fracture. $\mathrm{Zr}_{64.13} \mathrm{Cu}_{15.75} \mathrm{Ni}_{10.12} \mathrm{Al}_{10}$ BMG having $v$ of 0.377 showed global plasticity of $160 \%$, while $\mathrm{Zr}_{65} \mathrm{Cu}_{15} \mathrm{Ni}_{10} \mathrm{Al}_{10}$ BMG having $v$ of 0.355 showed nearly no plastic strain. $\mathrm{Pt}_{57.5} \mathrm{Cu}_{14.7} \mathrm{Ni}_{5.3} \mathrm{P}_{22.5}$ BMG, showing highest Poisson's ratio of 0.42 , was reported to 
show pronounced global plasticity of $20 \%$ under compression loading condition and permanent deformation and a strain exceeding 3\% before failure during bending of $4 \mathrm{~mm}$ thick samples (Schroers \& Johnson, 2004). Even though highly ductile BMGs show high values of Poisson's ratio, it is not clear whether the Poisson's ratio is the only relevant parameter reflecting good plasticity of BMG.

\section{BMG WITH POSITIVE HEAT OF MIXING ELEMENT}

One way to impose an inhomogeneity in atomic scale is to add small amount of alloying element having positive heat of mixing with constituting major elements. The repulsive interaction between atoms may be favorite to increase in local free volume and to reduce local elastic modulus, both can promote to increase the STZ density for relaxation of strain localization. Park et al., (2005a) has succeeded to improve plasticity of BMG by partial substitution of $\mathrm{Zr}$ by $\mathrm{Nb}$ in $\mathrm{Cu}-\mathrm{Ti}-\mathrm{Zr}-\mathrm{Nb}-\mathrm{Ni}-\mathrm{Si}$ BMG. $\mathrm{Nb}$ was selected as positive mixing enthalpies between $\mathrm{Nb}$ and constituting elements $\mathrm{Ti}$ and Zr. Fig. 1 shows the nominal compressive stressstrain curve for the BMG samples. The $\mathrm{Cu}_{47} \mathrm{Ti}_{33} \mathrm{Zr}_{11} \mathrm{Ni}_{8} \mathrm{Si}_{1}$ BMG sample exhibited elongation of about 3.3\%, while the $\mathrm{Cu}_{47} \mathrm{Ti}_{33} \mathrm{Zr}_{7} \mathrm{Nb}_{4} \mathrm{Ni}_{8} \mathrm{Si}_{1}$ BMG sample exhibited about $6.1 \%$ before fracture, indicating that the $\mathrm{Nb}$ substitution for $\mathrm{Zr}$ in the system resulted in the improvement of plasticity. Liu et al. (2013) reported that partial replacement of Co by $\mathrm{Cu}$ in $\mathrm{ZrCoAl} \mathrm{BMG} \mathrm{the} \mathrm{fracture} \mathrm{plastic} \mathrm{strain} \mathrm{changes} \mathrm{from} 1 \%$ to $12.4 \%$. Even though the alloys prepared with this method showed large plasticity in compression mode, they failed to show the existence of tensile elongation before fracture.

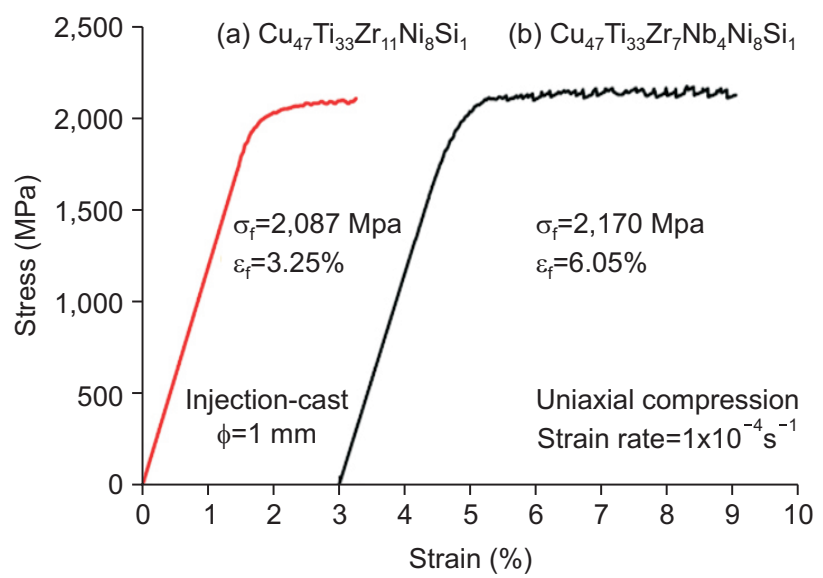

Fig. 1. Compressive stress strain curves for $\mathrm{Cu}_{47} \mathrm{Ti}_{33} \mathrm{Zr}_{11} \mathrm{Ni}_{8} \mathrm{Si}_{1}$ and $\mathrm{Cu}_{47} \mathrm{Ti}_{33} \mathrm{Zr}_{7} \mathrm{Nb}_{4} \mathrm{Ni}_{8} \mathrm{Si}_{1}$. Reused from the article of Park et al. (2005a) (J. Noncryst. Solid 351, 1232-1238) with original copyright holder's permission.

\section{BMG WITH PRE-STRAINING}

Considering local shear deformation in BMG contains dilatational effect, shear band exhibits higher local free volume than undeformed glassy matrix. Therefore pre-straining BMG under a confined mode such as rolling or shot peening may provide local inhomogeneity in free volume distribution and therefore local elastic modulus. Fig. 2 shows plane view of the BMG plate cold rolled up to the reduction ratio of $30 \%$. It can be noticed shear bands were developed during rolling. The density of the secondary (or tertiary) shear bands increased with increasing the area reduction ratio.

The rolled specimen showed increased plastic strain of about $13.5 \%$, compared with plastic strain of about $4.7 \%$ for ascast unrolled specimen (Park et al., 2005b). Enhancement of plasticity of BMG by applying rolling treatment were reported in other report (Yokoyama, 2003). It has been suggested that the atomic free volume in shear bands is larger than that in matrix of BMG (Spaepen, 1997). Therefore the rolled BMG specimen shows inhomogeneous distribution of free volume, elastic modulus, which is effective for distribution strain more uniformly throughout the specimen. The pre-strained BMG specimen exhibited reduced yield strength but enhanced ductility in compression test. However they have failed to show any significant tensile elongation before fracture.

Recently surface modification of BMG was applied to enhance plasticity by surface mechanical attrition treatment (SMAT) (Wang et al., 2014). The surface modified BMG specimen showed a gradient amorphous microstructures across the sample thickness and exhibited both a high strength of $2 \mathrm{GPa}$ and tensile elongation of $2 \% \sim 4 \%$ at room temperature. The observed tensile ductility was attributed to the gradient amorphous structure, which promotes multiple

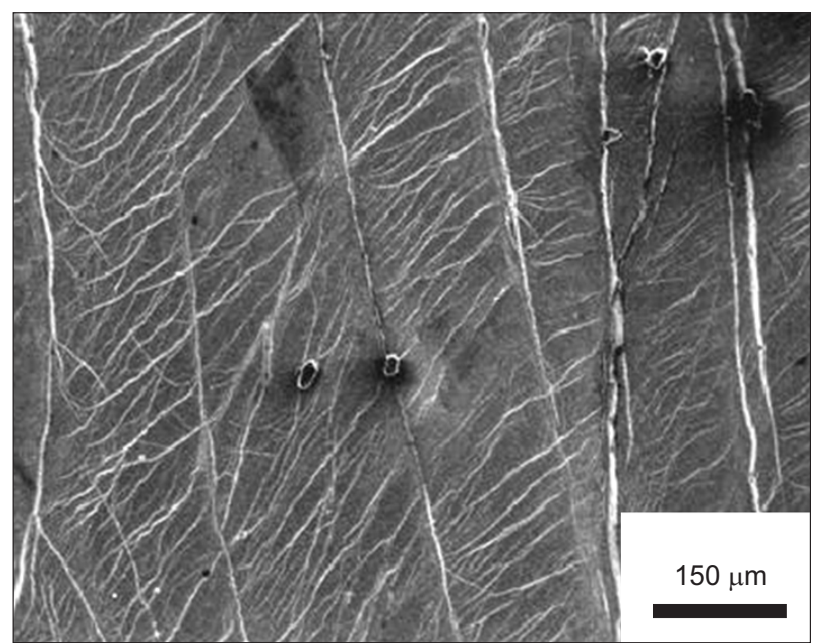

Fig. 2. Scanning electron microscope image of deformed surface taken from cold rolled $\mathrm{Ti}_{45} \mathrm{Zr}_{16} \mathrm{Be}_{20} \mathrm{Cu}_{10} \mathrm{Ni}_{9}$ BMG plate. 
shear banding while suppresses shear cracking at room temperature. The softened BMG surface offered easy sites for shear band initiation.

\section{BMG COMPOSITES}

Various types of BMG composites have been prepared to introduce microstructural heterogeneity in glassy matrix. The BMG composites contain various types of crystalline phase with a length scale ranging from a few $\mathrm{nm}$ to a few hundred $\mu \mathrm{m} . \mathrm{Zr}_{50} \mathrm{Cu}_{50}$ BMG specimen showing a microstructure consisted of a glassy phase containing fine crystalline particles with a size of about $5 \mathrm{~nm}$, exhibited showed high strength of $1,860 \mathrm{MPa}$ and a compressive plastic strain at room temperature of more than 50\% (Inoue et al., 2005). Simultaneous enhancements of strength and plasticity have been achieved by partial crystallization of Ti-Zr-Be$\mathrm{Cu}-\mathrm{Ni}$ BMG (Kim et al., 2003). The annealed specimen showed a microstructure consisted of finely distributed nano scaled quasicrystalline parilces in a glassy matrix. It is well known that structural relaxation causes specimen more brittle and harder than as-solidified amorphous specimen. Considering the structural relaxation is accompanied during the heat treatment, the simultaneous increases strength and compressive plasticity clearly indicates that the finely distributed quasicrystalline particles played a role in improving plasticity significantly. The enhancement of plasticity may be attributed to the difference in elastic modulus and to the structural similarity between quasicrystalline phase and glassy matrix as shown in Fig. 3. However, if the volume fraction of



Fig. 3. High-resolution transmission electron microscope image interface between nano-sized quasicrystal and amorphous matrix. Reused from the article of Kim et al. (2003) (Appl. Phys. Lett. 83, 3093-3095) with original copyright holder's permission. quasicrystalline phase is above a certain level the brittleness of quasicrystal deteriorated the ductility of composites.

In-situ BMG composites consisted of crystalline phase with a length scale of $\mu \mathrm{m}$ have been developed in several alloy systems including $\mathrm{Zr}$ based, Ti based and $\mathrm{Cu}$ based alloys (Hays et al., 2000; Das et al., 2005; Rim et al., 2013). The BMG composites can be classified into two different types: one is strain softening and the other is strain hardening BMG composites. The former case can be found in $\mathrm{Zr}$ - and Ti-based BMG composites, which consisted of primary crystallized $\beta$ dendrite embedded in a glassy matrix as shown in Fig. 4. Solute partitioning during dendritic growth

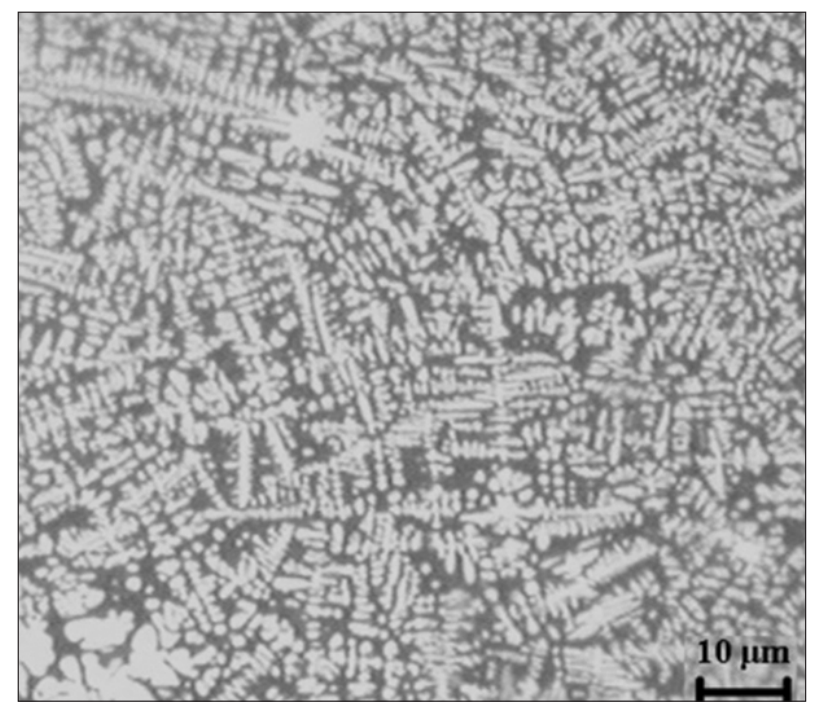

Fig. 4. Typical optical microstructure showing dendritically grown $\beta$ phase embedded in a glass matrix.



Fig. 5. Transmission electron microscope micorgraph showing deformation steps formed at interface between $\beta$ dendrite and glass matrix during deformation. 
stabilized the remaining liquid, which is solidifying into a glass during subsequent cooling process. Therefore the size and volume fraction of $\beta$ phase can be tuned by controlling alloy composition and cooling condition (Hofmann et al., 2008). Even though theses composites exhibited an improvement in tensile ductility, they showed a macroscopic strain softening phenomenon with an early onset of necking because of a lack of work hardening mechanisms. The interface between the dendrite and glass matrix may not be as effective as grain boundary in polycrystalline materials in acting as an obstacle hindering dislocation motion because the glass can be a sink of dislocation. It can be noticed the formation of slip step at the interface observed deformed BMG composites as shown in Fig. 5. Therefore the increase in dislocation density in crystalline $\beta$ phase during deformation will be limited and limited strain hardening is expected. A new type of strain hardening BMG composites has been developed in $\mathrm{Ti}$ based BMG composites (Kim et al., 2011). $\mathrm{Ti}_{48} \mathrm{Zr}_{27} \mathrm{Ni}_{6} \mathrm{Be}_{14} \mathrm{Ta}_{5}$ alloy showing a mixture of dendritically grown $\beta$ phase and glassy matrix exhibited large tensile ductility with significant work hardening behavior under tensile stress mode. This unique property is attributed to the deformation-induced transformation of crystalline dendrites into martensite phase. The strain hardening BMG composites can be found in $\mathrm{Cu}-\mathrm{Zr}$ and $\mathrm{Cu}-\mathrm{Zr}-\mathrm{Al} \mathrm{BMG}$ composites containing B2 phase distributed in glassy matrix (Das et al., 2005; Qiao et al., 2011) The BMG composites showed a reduced yield strength but strong strain hardening behavior after yielding before mechanical instability takes place during tensile test. Deformation induced martensitic transformation took place from B2 phase into B19' phase, which induced local deformation in glassy matrix surrounding the crystalline phase at low applied stress. The main disadvantage of this BMG composites is the difficulty in phase control. The B2 phase has similar composition with that of glassy matrix phase. During cooling the nucleated primary crystal continues to grow until the remaining liquid solidified into a glassy phase at glass transition temperature. Even though the microstructure such as size and volume fraction can be controlled by controlling processing condition in principle, practical control is very difficult, resulting in low level of reproducibility in microstructure of this type of BMG composites.

Enhanced plasticity in BMG composites is attributed to the heterogeneity in microstructure. Due to the differences in elastic modulus and elastic limit between glassy matrix and crystalline phase, inhomogeneous stress field builds at region around the crystalline phase. Either elastic or plastic misfit strain can create stress concentration, depending on relative yield strength between two phases and crystal orientation. Due to the stress concentration, yielding takes place only at a localized region at an applied stress far lower than the yield strengths of monolithic glass phase (Ott et al., 2005). This localized yielding corresponds to the initiation of shear band. Further propagation of shear band does not continue until the yield criterion is satisfied because the shear stress is insufficient to sustain shear band propagation. For BMG composites containing nano crystalline particles, multiple shear band initiation at the interface seems to the main mechanism for the plasticity enhancement, while not only initiation of shear band at interface but also blocking of shear band propagation are effective for the composites containing $\mu \mathrm{m}$ sized crystalline phase.

It is believed that microstructural and physical characteristics of the secondary phases including size, morphology and volume fraction, elastic modulus and yield strength play an important role in controlling the tensile ductility of BMG composites (Fu et al., 2007; Abdelijawad et al., 2011). Finally the enhancement of plasticity of BMG could be achieved by homogenous distribution of locally weak region, where local strain can be initiated. This is contrary to introducing obstacles hindering dislocation motion for strengthening in crystalline materials. Therefore enhancement of plasticity of $\mathrm{BMG}$ is accompanied with some penalty of strength loss.

\section{SUMMARY}

BMG showing high strength, high elastic limit, corrosion resistance and good wear resistance and soft magnetic properties has a potential application as structural materials. However, the limited plasticity and lack of tensile ductility should be solved for real structural application. In this paper researches on the enhancement of plasticity of BMG were reviewed briefly. Introducing heterogeneous structure in glass will be effective to induce more STZs active for multiple shear band initiation and also to block the propagating shear band. Several methods such as alloy design for high Poisson ratio, addition of alloying element having positive heat of mixing, pre-straining BMG and variety of BMG composites have been developed for homogenous distribution of locally weak region, where local strain can be initiated. This is contrary to introducing obstacles hindering dislocation motion for strengthening in crystalline materials. Therefore, enhancement of plasticity of BMG is accompanied with some penalty of strength loss.

\section{CONFLICT OF INTEREST}

No potential conflict of interest relevant to this article was reported. 


\section{REFERENCES}

Abdelijawad F, Fontus M, and Haataja M (2011) Ductility of bulk metallic glass composites: microstructural effects. Appl. Phys. Lett. 98, 031909.

Ashby M F and Greer A L (2006) Metallic glasses as structural materials. Scr. Mater. 54, 321-326.

Das J, Tang M B, Kim K B, Theissmann R, Baier F, Wang W H, and Eckert J (2005) "Work-hardenable" ductile bulk metallic glass. Phys. Rev. Lett. 94, 205501.

Demetriou M D, Launey M E, Garrett G, Schramm J P, Hofmann D C, Johnson W L, and Ritchie R O (2011) A damage-tolerant glass. Nature Mater. 10, 123-128.

Falk M L and Langer J S (1998) Dynamics of viscoplastic deformation in amorphous solids. Phys. Rev. E 57, 7192-7205.

Fu X L, Li Y, and Schuh C A (2007) Mechanical properties of metallic glass matrix composite: effect of reinforcement character and connectivity. Scr. Mater. 56, 617-620.

Greaves G N, Greer A L, Lakes R S, and Rouxel T (2011) Poisson's ratio and modern materials. Nature Mater. 10, 823-837.

Hays C C, Kim C P, and Johnson W L (2000) Microstructure controlled shear band pattern formation and enhanced plasticity of bulk metallic glasses containing in situ formed ductile phase dendrite dispersions. Phy. Rev. Letters 84, 2901-2904.

Hofmann D C, Suh J-Y, Wiest A, Duan G, Lind M-L, Demetriou M D, and Johnson W L (2008) Designing metallic glass matrix composites with high toughness and tensile ductility. Nature 451, 1085-1089.

Inoue A, Zhang W, Tsurui T, Yavari A R, and Greer A L (2005) Unusual room-temperature compressive plasticity in nanocrystaltoughened bulk copper-zirconium glass. Philos. Mag. Lett. 85, 221-229.

Kim C P, Oh Y S, Lee S, and Kim N J (2011) Realization of high tensile ductility in a bulk metallic glass composite by the utilization of deformation-induced martensitic transformation. Scr. Mater. 65, 304-307.

Kim Y C, Na J H, Park J M, Kim D H, Lee J K, and Kim W T (2003) Role of nanometer-scale quasicrystals in improving the mechanical behavior of Ti-based bulk metallic glasses. Appl. Phys. Lett. 83, 3093-3095.

Lewandowki J J, Wang W H, and Greer A L (2005) Intrinsic plasticity or brittleness of metallic glasses. Philos. Mag. Lett. 85, 77-87.

Liu Y H, Wang G, Wang R J, Zhao D Q, Pan M X, and Wang W H (2007) Super plastic bulk metallic glasses at room temperature. Science 315, 1385-1388.

Liu Z, Chan K C, and Liu L (2013), Effect of alloying elements with positive heat of mixing on the free volume and compressive plasticity in
ZrCoCuAl bulk metallic glasses. Mater. Trans. 54, 2209-2214.

Lund A C and Schuh C A (2003) Yield surface of a simulated metallic glass. Acta Mater 51, 5399-5411.

Nishiyama N, Takenaka N, Miura H, Saidoh N, Zeng Y, and Inoue A (2013) The world's biggest glassy alloy ever made. Intermetallics 30, 19-24.

Ott R T, Sansoz F, Molinari J F, Almer J, Ramesh K T, and Hufnagel T C (2005) Micromechanics of deformation of metallic-glass-matrix composites from in situ synchrotron strain measurements and finite element modeling. Acta Mater. 53, 1883-1893.

Park E S, Kim D H, Ohkubo T, and Hono K (2005a) Enhancement of glass forming ability and plasticity by addition of $\mathrm{Nb}$ in $\mathrm{Cu}-\mathrm{Ti}-\mathrm{Zr}-\mathrm{Ni}-\mathrm{Si}$ bulk metallic glasses. J. Non-cryst. Solid 351, 1232-1238.

Park J M, Park J S, Kim J-H, Lee M H, Kim W T, and Kim D H (2005b) Ti-based bulk metallic glass with high cold workability at room temperature. Mater. Sci. Forum 475-479, 3431-3434.

Poon S J, Zhu A, and Shiflet G J (2008) Poisson's ratio and intrinsic plasticity of metallic glasses. Appl. Phys. Lett. 92, 261902.

Qiao J W, Sun A C, Huang E W, Zhang Y, Liaw P K, and Chuang C P (2011) Tensile deformation micromechanisms for bulk metallic glass matrix composites: from work-hardening to softening. Acta Mater. 59, 41264137.

Rim K R, Park J M, Kim W T, and Kim D H (2013) Tensile necking and enhanced plasticity of cold rolled b-Ti dendrite reinforced Ti-based bulk metallic glass matrix composite. J. Alloys Comp. 579, 253-258.

Schroers J and Johnson W L (2004) Ductile bulk metallic glass. Phys. Rev. Lett. 93, 255506.

Spaepen F (1976) A microscopic mechanism for strady state inhomogeneous flow in metallic glasses. Acta Metall. 25, 407-415.

Wang Q, Yang Y, Jiang H, Liu C T, Ruan H H, and Lu J (2014) The atomicscale mechanism for the enhanced glass-forming-ability of a $\mathrm{Cu}-\mathrm{Zr}$ based bulk metallic glass with minor element additions. Sci. Rep. 4, 04648.

Yokoyama Y (2003) Ductility improvement of Zr-Cu-Ni-Al glassy alloy. J. Non-cryst. Solids 316, 104-113.

Yokoyama Y, Fujita K, Yavari A R, and Inoue A (2009) Malleable hypoeutectic Zr-Ni-Cu-Al bulk glassy alloys with tensile plastic elongation at room temperature. Phil. Mag. Lett. 89, 322-334.

Zhang T, Inoue A, and Masumoto T (1991) Amorphous Zr-Al-TM (TM=Co, $\mathrm{Ni}, \mathrm{Cu}$ ) alloys with significant supercooled liquid region of over $100 \mathrm{~K}$. Mater. Trans., JIM 32, 1005-1010. 